\title{
Increased cardiovascular risk in thyroid cancer patients taking levothyroxine: a nationwide cohort study in Korea
}

\author{
Beomseok Suh',*, Dong Wook Shinn",*, Youngmin Park ${ }^{3}$, Hyunsun Lim ${ }^{4}$, Jae Moon Yun ${ }^{1}$, Sun Ok Song ${ }^{5}$, \\ Jin Ho Park', BeLong Cho ${ }^{1,2}$ and Eliseo Guallar ${ }^{6}$
}

${ }^{1}$ Department of Family Medicine, Seoul National University Hospital, Seoul, Republic of Korea, ${ }^{2}$ Department of Family Medicine and Supportive Care Center, Samsung Medical Center, Seoul, Republic of Korea, ${ }^{3}$ Department of Family Medicine, National Health Insurance Service Ilsan Hospital, Goyang-si, Gyeonggi-do, Republic of Korea, ${ }^{4}$ Department of Policy Research Affairs, National Health Insurance Service Ilsan Hospital, Goyang-si, Gyeonggi-do, Republic of Korea, ${ }^{5}$ Division of Endocrinology, Department of Internal Medicine, National Health Insurance Service Ilsan Hospital, Goyang-si, Gyeonggi-do, Republic of Korea, and ${ }^{6}$ Department of Medicine and Welch Center for Prevention, Epidemiology, and Clinical Research, Johns Hopkins Medical Institutions, Baltimore, Maryland, USA

*(B Suh and D W Shin contributed equally to this work)

Correspondence should be addressed to $Y$ Park Email davidympark@gmail.com

\section{Abstract}

Objective: Many thyroid cancer patients are exposed to long-term thyroid-stimulating hormone (TSH) suppression, often as lifetime treatment, and are consequently at risk for cardiovascular disease. We investigated the incidence of coronary heart disease (CHD) and ischemic stroke among thyroid cancer patients compared with matched control subjects.

Design: Retrospective cohort study.

Methods: A total of 182419 subjects who received thyroidectomy for thyroid cancer during 2004-2012 were selected from the Korean National Health Insurance data, which cover approximately $97 \%$ of the entire Korean population. Propensity score matching was used to select non-cancer controls. Cox proportional hazards regression analysis was used to determine relative risk of coronary heart disease and ischemic stroke. Mean follow-up was 4.32 years.

Results: Thyroid cancer patients had elevated risk for $\mathrm{CHD}$ and ischemic stroke with hazard ratio (HR) of 1.15 (95\% confidence interval (Cl): 1.10-1.22) and 1.15 (1.09-1.22), respectively. This risk was increased in those who took a higher dosage of levothyroxine (HR: 1.47, 95\% Cl: 1.34-1.60 for CHD and HR: 1.56, 95\% Cl: 1.42-1.72 for ischemic stroke among those who took $\geq 170 \mu \mathrm{g}$ /day levothyroxine). Although risk of atrial fibrillation was dose-dependently associated with levothyroxine dosage, it represents only a small proportion of ischemic stroke incidence $(4.4 \%, 128 / 2914)$.

Conclusions: The risk for CHD and ischemic stroke was higher in thyroid cancer patients who received thyroidectomy, and the dosage of levothyroxine administered appears to play a major role. Greater caution is suggested for the screening and treatment of thyroid cancer and subsequent TSH suppression therapy, as well as proper management for cardiovascular disease prevention. 


\section{Introduction}

Thyroid-stimulating hormone (TSH) suppression using levothyroxine is routinely prescribed to reduce thyroid cancer recurrence after total thyroidectomy with or without radioactive iodine (RAI) ablation $(1,2)$. Previous US (1) and European (2) guidelines recommended TSH suppression of $<0.1 \mathrm{mIU} / \mathrm{L}$ for high-risk thyroid cancer patients and between 0.1 and 1-2 mIU/L for low-risk patients and most thyroid cancer patients have been exposed to long-term TSH suppression, in many cases as lifetime treatment.

Hyperthyroidism due to thyroid disease is a wellknown risk factor for atrial fibrillation (3) and ischemic stroke (4), and may also precipitate angina or myocardial infarction in patients with underlying coronary heart disease (CHD) (5). Similarly, overt or subclinical hyperthyroidism due to supraphysiologic doses of levothyroxine for TSH suppression may also have adverse cardiovascular effects (6), including atrial fibrillation (7), diastolic dysfunction (8) and left ventricular hypertrophy (9). Small hospital-based studies in the United States $(n=524)$ and Finland $(n=901)$ reported increased cardiovascular mortality or incidence in patients with differentiated thyroid cancer compared to controls chosen from other cohorts, particularly in those with low TSH levels $(10,11)$, but large-scale data on a population level are lacking.

We therefore conducted a large cohort study to investigate the incidence of $\mathrm{CHD}$ and ischemic stroke among post-thyroidectomy thyroid cancer patients compared with non-cancer controls and explored the possible pathophysiological mechanisms involved.

\section{Subjects and methods}

\section{Study population}

We conducted a retrospective cohort study based on the Korean National Health Insurance (KNHI) database, which includes inpatient visits, outpatient visits, procedures and prescription medications covered by the KNHI, a mandatory universal public health insurance system that covers the entire Korean population except for Medicaid beneficiaries in the lowest income bracket (approximately $3 \%$ of the population). KNHI collects information necessary for reimbursement of each medical service including age, sex, monthly insurance premium (a proxy for economic status, as insurance premium is determined by income in Korea), residence, disability status, disease codes and costs incurred. The KNHI database has been widely used for epidemiological studies and is described in detail elsewhere $(12,13,14)$. This study used cohort data (NHIS-2017-1-016), provided by KNHI. This study adhered to the tenets of the Declaration of Helsinki and was approved by the Institutional Review Board of the National Health Insurance Service Ilsan Hospital, Gyeonggi-do, Korea. Written informed consent was waived.

The study population included all subjects who received thyroidectomy (either lobectomy or total) for thyroid cancer (ICD-10 C73) from January 1, 2004 to December 31, $2012(n=214$ 084). We excluded patients with a prior diagnosis of other cancer (C00-C97 except C73, $n=7590)$, CHD (I20-I25, $n=8029$ ), ischemic stroke (I63, $n=5245$ ), congestive heart failure (I50, $n=2481$ ), valvular heart disease (I34-I37, $n=550)$ or atrial fibrillation (I48, $n=3492)$, and those with previous history of levothyroxine medication $(n=4278)$ within 1 year of thyroidectomy. The final number of thyroid cancer patients enrolled was 182419 (Fig. 1).

For selection of the control group, we used 1:1 propensity score matching to reduce bias in the statistical analysis of observational data (15). Matching was serially performed year by year so that incident thyroid cancer cases were matched to control cases based on information at the time of cancer development (e.g., patients who were diagnosed in the year 2004 were matched to control individuals available in the same year, and baseline characteristics for matching were derived from the 2004 data). After applying identical exclusion criteria to those implemented for the thyroid cancer patient group (except for ' 1 year prior to thyroidectomy'), propensity scores were estimated using logistic regression based on baseline age, sex, residence, insurance premium level, disability, hypertension (I10, I15), diabetes (E10-E14) and dyslipidemia (E78), and matched with a Mahalanobis matching algorithm with a caliper of 0.0001. Control subjects were assigned an index date corresponding to the date of thyroidectomy of their matched thyroid cancer patients.

This study was approved by the Institutional Review Board of the National Health Insurance Service Ilsan Hospital, Gyeonggi-do, Korea. The need for written informed consent was waived.

\section{Outcomes and measures}

Similar to previous studies $(16,17)$, CHD incidence and ischemic stroke incidence were defined as inpatient 


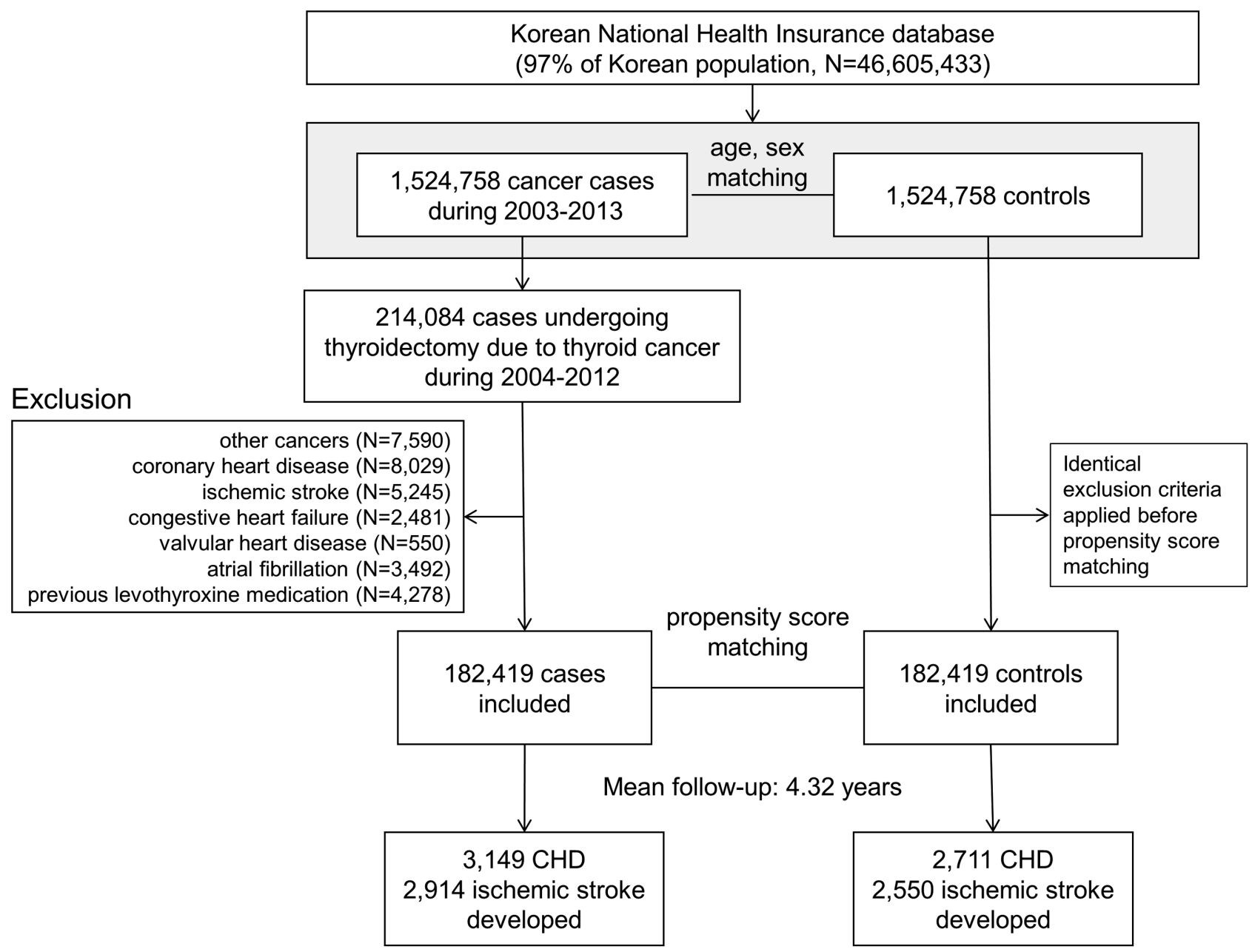

\section{Figure 1}

Selection scheme for study population.

hospitalization from KNHI claims records, registered after baseline. Atrial fibrillation was defined as claims for atrial fibrillation diagnosis after baseline up to 3 months after the date of ischemic stroke in acknowledgement of the fact that the diagnosis of atrial fibrillation often occurs during diagnostic work-up for causes of ischemic stroke.

Prescription claims data for radioiodine ablation therapy and levothyroxine medication were used. Dosage of levothyroxine medication was determined as the mean dosage of all prescriptions in terms of total daily administration ( $\mu \mathrm{g} /$ day). For subjects with events (i.e., CHD, ischemic stroke or death) the mean dosage was calculated up to the time of the event.

\section{Statistical analysis}

Descriptive statistics were used to determine the basic characteristics of the study population. Thyroid cancer patients were further categorized by thyroidectomy type (lobectomy vs total) and by the dosage level of levothyroxine as quartiles $(<115,115-144,145-169$, and $\geq 170 \mu \mathrm{g}$ /day). Insurance premium level was categorized into low, middle and high based on insurance premium brackets corresponding to the following income levels: 1-10, low; 11-15, middle; 16-20, high. Residence was categorized into three major types of residential areas: metropolitan, urban and suburban/rural.

Kaplan-Meier curves were used to graphically describe the cumulative incidence of CHD and ischemic stroke with time. Cox proportional hazards regression analysis was used to determine the hazard ratios for CHD and ischemic stroke incidence comparing cancer patients and noncancer patients, with cancer patients further categorized by treatment type and levothyroxine dose. Survival time was calculated from the thyroidectomy or index date until the date of cardiovascular events, censor date (death from 
other causes or outmigration), or December 31, 2013, whichever came first. We also investigated the relative risk for atrial fibrillation incidence by levothyroxine dosage levels compared with control subjects by multivariable Cox proportional hazards regression adjusted by age, sex, hypertension, diabetes, and dyslipidemia. To investigate the involvement of atrial fibrillation in ischemic stroke incidence, we assigned control subjects without atrial fibrillation incidence as controls and calculated the relative risk by atrial fibrillation incidence and levothyroxine dosage using multivariable Cox proportional hazards regression.

Factors associated with CHD or ischemic stroke incidence among thyroid cancer patients were also separately analyzed by Cox proportional hazards regression. All regressions were checked for proportionality prior to analyses. As high body weight may be related to both levothyroxine dosage and CHD or ischemic stroke (18), subgroup analyses were performed with subjects who participated in the national screening examination within 2 years from date of thyroidectomy and therefore had available data for baseline body weight and smoking data ( $n=112129 ; 61.5 \%$ of total study participants) (16). Mean levothyroxine dosage was divided by body weight, and mean levothyroxine dosage per kilogram was again categorized by quartiles for the subsequent analysis. All statistical analyses were performed using STATA version 14.0 (StataCorp) and results with $P$ values less than 0.05 were considered significant.

\section{Results}

\section{Characteristics of study population}

As expected from the matching process, age, sex, hypertension, diabetes and dyslipidemia rates were similar between thyroid cancer patients and controls (Table 1). Mean age was 47.0 years (SD 11.3) and $84.2 \%$ of the study population were women. Most participants were categorized as high income, and $24.4 \%$ had hypertension, $14.1 \%$ had diabetes and $23.9 \%$ had dyslipidemia.

For case subjects, among thyroid cancer patients who received thyroidectomy virtually all $(96.4 \%)$ received total thyroidectomy, over half $(57.3 \%)$ received postthyroidectomy radioiodine ablation therapy, and $48.4 \%$ were administered an average dosage of levothyroxine $\geq 145 \mu \mathrm{g} /$ day post thyroidectomy.

\section{Cardiovascular disease incidence in thyroid cancer patients compared with matched controls}

During the mean follow-up of 4.3 years 3149 CHD and 2914 ischemic stroke events developed in thyroid cancer patients (event rate: 4.01 and 3.71 per 1000 person-years, respectively), compared to 2711 and 2550 respectively in the control group. Compared to the matched control group, thyroid cancer patients had elevated CHD risk with hazard ratio (HR): 1.15 and 95\% confidence interval (CI): 1.10-1.22 (Fig. 2).

This risk for CHD was especially marked in those who received total thyroidectomy (HR: 1.18, 95\% CI: 1.12-1.24) and in those who took higher dosage of

Table 1 Basic characteristics of study population.

\begin{tabular}{|c|c|c|c|}
\hline & Control* & Case $^{\dagger}$ & $P$-value \\
\hline Total number, $n$ & 182419 & 182419 & \\
\hline Age, mean (s.D.), years & $47.0(11.3)$ & $47.0(11.3)$ & 0.665 \\
\hline Sex, $n(\%)$, female & $153578(84.2)$ & $153524(84.2)$ & 0.806 \\
\hline $\begin{array}{l}\text { Insurance premium } \\
\text { level, } n(\%)\end{array}$ & & & 0.991 \\
\hline Low & $12963(7.1)$ & $12976(7.1)$ & \\
\hline Middle & 42905 (23.5) & 42929 (23.5) & \\
\hline High & $126551(69.4)$ & $126514(69.4)$ & \\
\hline Residence, $n(\%)$ & & & 0.996 \\
\hline Metropolitan & $59862(32.8)$ & $59884(32.8)$ & \\
\hline Urban & 84735 (46.5) & $84708(46.4)$ & \\
\hline Suburban/rural & $37822(20.7)$ & 37827 (20.7) & \\
\hline Disability, $n(\%)$ & $1843(1.0)$ & $1873(1.0)$ & 0.621 \\
\hline Hypertension, $n(\%)$ & $44455(24.4)$ & $44492(24.4)$ & 0.887 \\
\hline Diabetes, $n(\%)$ & $25625(14.1)$ & $25678(14.1)$ & 0.801 \\
\hline Dyslipidemia, $n$ (\%) & 43647 (23.9) & 43669 (23.9) & 0.924 \\
\hline \multicolumn{4}{|c|}{ Type of thyroidectomy, $n(\%)$} \\
\hline Unilateral lobectomy & - & $6584(3.6)$ & \\
\hline Total thyroidectomy & - & $175835(96.4)$ & \\
\hline $\begin{array}{l}\text { Radioiodine } \\
\quad \text { ablation, } n(\%)\end{array}$ & - & $104517(57.3)$ & \\
\hline \multicolumn{4}{|c|}{ Levothyroxine dosage, $n(\%)$} \\
\hline $\begin{array}{l}\text { Lowest quartile } \\
(<115 \mu \mathrm{g} / \text { day })\end{array}$ & - & $46675(25.6)$ & \\
\hline $\begin{array}{l}\text { 2nd quartile } \\
(115-144 \mu \mathrm{g} / \text { day })\end{array}$ & - & $47484(26.0)$ & \\
\hline $\begin{array}{l}\text { 3rd quartile } \\
(145-169 \mu \mathrm{g} / \mathrm{day})\end{array}$ & - & $45250(24.8)$ & \\
\hline $\begin{array}{l}\text { Highest quartile } \\
\text { ( } \geq 170 \mu \mathrm{g} / \text { day })\end{array}$ & - & $43010(23.6)$ & \\
\hline \multicolumn{4}{|l|}{ Subgroup $(n=112129)$} \\
\hline $\begin{array}{l}\text { Body weight, mean } \\
\text { (S.D.), kg }\end{array}$ & & $61(85.7)$ & \\
\hline \multicolumn{4}{|l|}{ Smoking status } \\
\hline Never & & $96103(85.7)$ & \\
\hline Former & & $6700(6.0)$ & \\
\hline Current & & $9326(8.3)$ & \\
\hline
\end{tabular}

*Control group selected via 1:1 propensity score matching in respect to the case group based on age, sex, insurance premium level, residence, disability, hypertension, diabetes, and dyslipidemia. ${ }^{\dagger}$ Post-thyroidectomy thyroid cancer patients. 
levothyroxine: patients who received $145-169 \mu \mathrm{g} /$ day or $\geq 170 \mu \mathrm{g} /$ daylevothyroxinehadHR:1.19(95\%CI:1.07-1.31) and HR: 1.47 (95\% CI: 1.34-1.60), respectively. Thyroid cancer patients showed increased risk of ischemic stroke with HR: 1.15 (95\% CI: 1.09-1.22). Ischemic stroke risk was marked among those who received total thyroidectomy (HR: 1.16, 95\% CI: 1.10-1.22) and in those who took a higher dosage of levothyroxine: patients who took $145-169 \mu \mathrm{g} /$ day or $\geq 170 \mu \mathrm{g} /$ day levothyroxine had HR: 1.22 (95\% CI: 1.10-1.36) and HR: 1.56 (95\% CI: 1.42-1.72), respectively, for risk of ischemic stroke (Fig. 3).
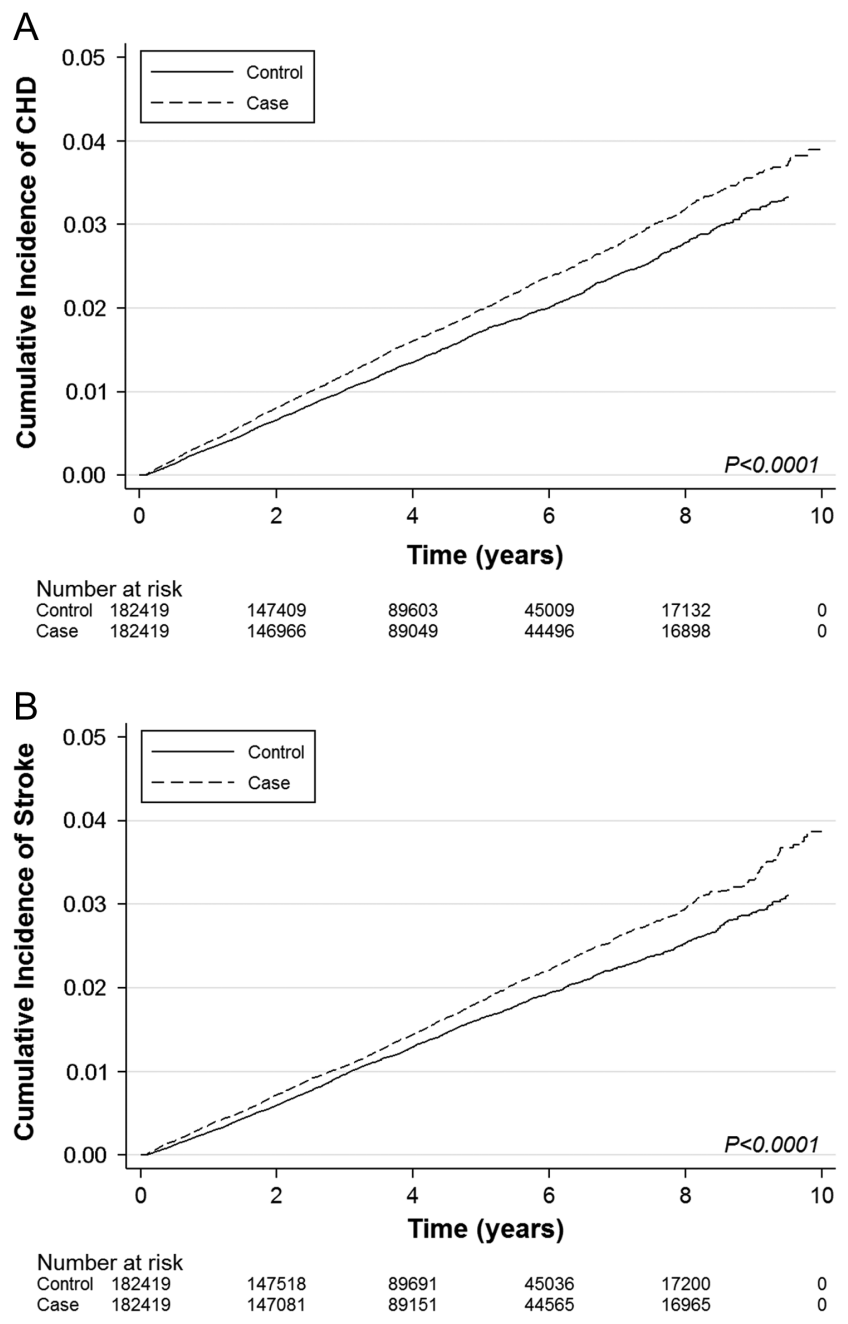

\section{Figure 2}

Kaplan-Meier curves for incidence of coronary heart disease and ischemic stroke among thyroid cancer patients. KaplanMeier curves for coronary heart disease incidence (Panel A) and ischemic stroke incidence (Panel B), where postthyroidectomy thyroid cancer patients (case) are compared to matched controls. $P$ values indicate results from log-rank tests.

\section{Risk of atrial fibrillation in thyroid cancer patients}

Thyroid cancer patients were also more likely to develop atrial fibrillation when the dosage of administered levothyroxine was high: compared to the control group, those who took $<115,115-144,145-169$ and $\geq 170 \mu \mathrm{g} /$ day had adjusted hazard ratio (aHR) of 1.43 (95\% CI: 1.27-1.62), 1.41 (1.26-1.58), 1.66 (1.49-1.85), and 1.78 (1.60-1.98), respectively, as shown in Fig. 4. The dosage of levothyroxine did not appear to significantly affect the risk of ischemic stroke risk upon atrial fibrillation occurrence: among case subjects with incident atrial fibrillation, those who took $<145 \mu \mathrm{g} /$ day levothyroxine had aHR 2.03 (95\% CI: $1.55-2.67)$ and those who took $\geq 145 \mu \mathrm{g} /$ day had aHR 2.29 (95\% CI: 1.82-2.89).

\section{Factors associated with cardiovascular disease incidence in thyroid cancer patients}

Among thyroid cancer patients, when the 2nd quartile group (in terms of mean levothyroxine dosage) was considered as the reference group, those who took either a lower or higher dosage of levothyroxine showed increased risk for both CHD and ischemic stroke, suggesting a J-shaped risk pattern (Table 2). In subgroup analyses of body weight and smoking data, the associations between mean levothyroxine dosage per kilogram and CHD or ischemic stroke incidence remained consistent, albeit slightly attenuated by the addition of additional variables in the regression models (Table 3 ).

\section{Discussion}

To our knowledge, this is the first population-based study to directly investigate the relative risk of CHD and ischemic stroke incidence among thyroid cancer patients. Consistent with previous studies $(10,11)$, we report an increased incidence of CHD and ischemic stroke among thyroid cancer patients compared to controls and showed that post-thyroidectomy levothyroxine dosage, which serves as a proxy marker for level of TSH suppression, is a key factor in such risk. Our study suggests that cardiovascular risk should be taken into consideration when the target level for TSH suppression is determined (6), and support recent recommendations that called for a more cautious approach in the screening and treatment of thyroid cancer and subsequent TSH suppression therapy $(19,20)$. 
Coronary Heart Disease Incidence

Thyroid cancer patients $\quad 784969.6 \quad 3149 \quad 4.01$ $\begin{array}{lllll}\text { Unilateral lobectomy } \quad 33767.7 & 134 & 3.97\end{array}$ $\begin{array}{llll}\text { Total thyroidectomy } \quad 751201.9 & 3015 & 4.01\end{array}$ Radioiodine ablation(-) $\quad 323046.9 \quad 1241 \quad 3.84$ Radioiodine ablation(+) $\quad 461922.8 \quad 1908 \quad 4.13$ LT4 $<115 \mathrm{mcg} / \mathrm{d} \quad 170026.8 \quad 619 \quad 3.64$ LT4 115-144mcg/d $\quad 201693.4 \quad 543 \quad 2.69$ LT4 145-169mcg/d $\quad 198179.1 \quad 831 \quad 4.19$ LT4 $\geq 170 \mathrm{mcg} / \mathrm{d} \quad 215070.4 \quad 1156 \quad 5.37$

Ischemic Stroke Incidence

Thyroid cancer patients $\quad 785742.6 \quad 2914 \quad 3.71$

$\begin{array}{lllll}\text { Unilateral lobectomy } \quad 33835.5 & 106 & 3.13\end{array}$

$\begin{array}{llll}\text { Total thyroidectomy } & 751907.1 & 2808 & 3.73\end{array}$

Radioiodine ablation(-) $\quad 323019.3 \quad 1213 \quad 3.76$

Radioiodine ablation(+) $\quad 462723.2 \quad 1701 \quad 3.68$

LT4 < 115mcg/d $\quad 170111.2 \quad 554 \quad 3.26$

LT4 115-144mcg/d $\quad 201690.9 \quad 537 \quad 2.66$

LT4 145-169mcg/d $\quad 198302.7 \quad 792 \quad 3.99$

LT4 $\geq 170 \mathrm{mcg} / \mathrm{d} \quad 215637.8 \quad 1031 \quad 4.78$

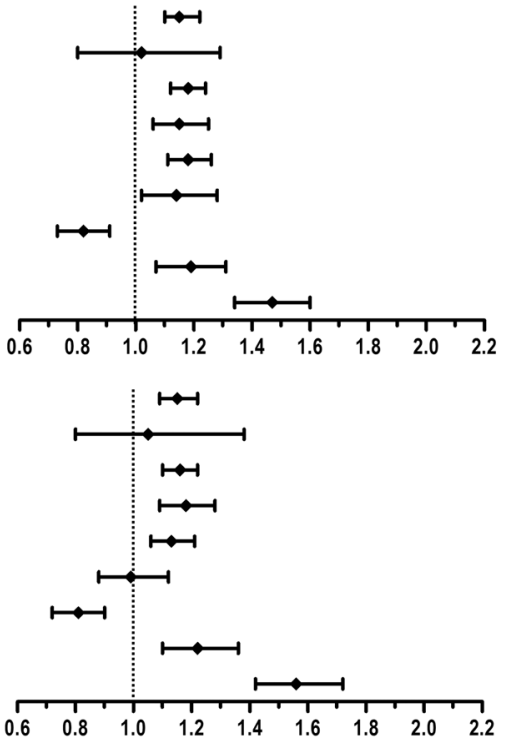

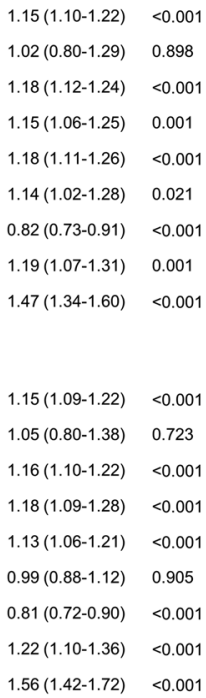

\section{Figure 3}

Forest plots for coronary heart disease and ischemic stroke incidence among thyroid cancer patients and matched controls. Hazard ratios were determined by univariable Cox proportional hazards regression analysis of specific case subjects compared to individually matched controls. Rates are indicated per 1000 person-years. LT4, levothyroxine; TT, total thyroidectomy; UL, unilateral lobectomy.
The pathophysiological mechanism for increased incidence of CHD and ischemic stroke remains largely unknown (10). Systolic hypertension, arterial stiffness, enhanced LDL oxidation and hypercoagulability were suggested as potential mechanisms for the associations $(21,22)$. In addition, changes in heart function or dysrhythmia were postulated to cause CHD (17). Our findings are consistent with previous studies $(10,23)$ in which mild or subclinical hyperthyroidism were reported to be associated with elevated cardiovascular mortality.

One major mechanism by which TSH suppression leads to ischemic stroke is atrial fibrillation (24). In our study, atrial fibrillation developed more often in thyroid cancer patients, with a higher incidence in subjects who were administered a higher levothyroxine dosage, and development of atrial fibrillation during follow-up was associated with a 2-2.5 times greater risk of developing ischemic stroke. Therefore, although current guidelines lack any recommendations for regular atrial fibrillation screening it may be warranted after thyroidectomy in those taking levothyroxine, and once atrial fibrillation is detected these patients would likely benefit from more aggressive stroke prevention measures, including anticoagulant medication $(25,26)$. Future studies are needed to determine the most appropriate approach to screening and management of atrial fibrillation in thyroid cancer patients.

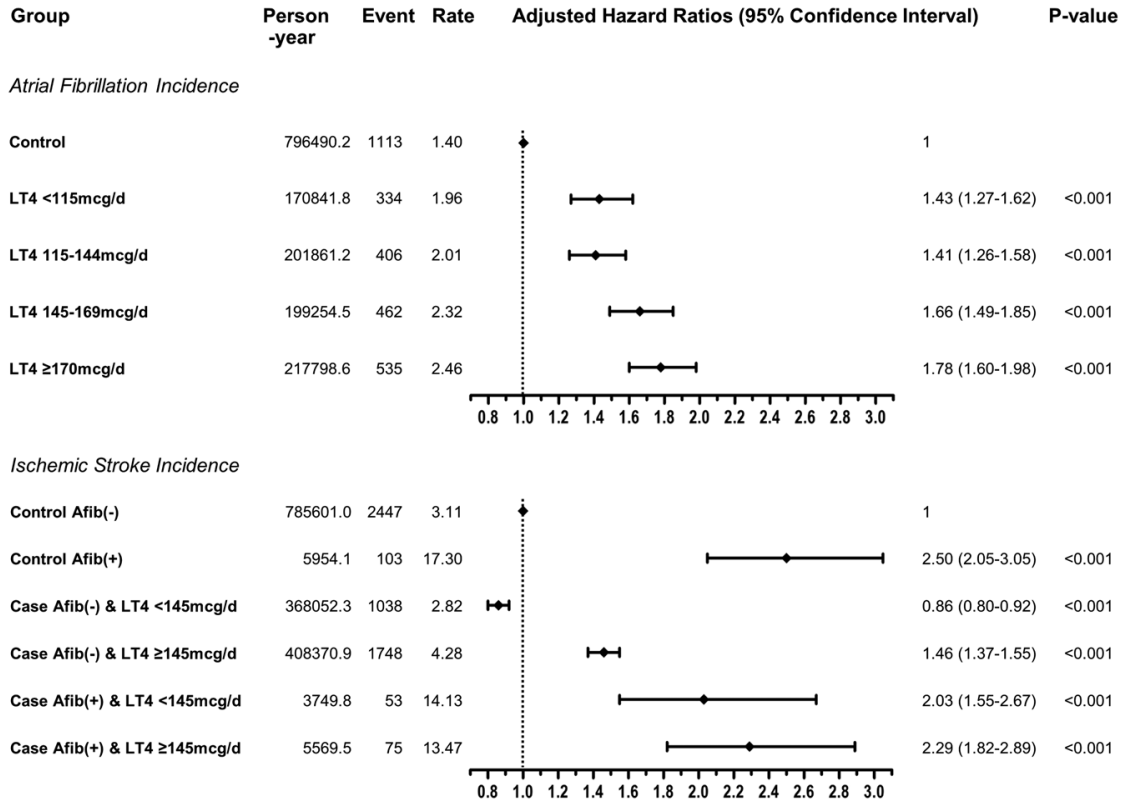

\section{Figure 4}

Involvement of atrial fibrillation in risk of ischemic stroke incidence among thyroid cancer patients. Hazard ratios were determined by multivariable Cox proportional hazards regression analysis adjusted by age, sex, hypertension, diabetes, and dyslipidemia. Rate is indicated per 1000 person-years. Afib, atrial fibrillation; LT4, levothyroxine. 
Table 2 Factors associated with cardiovascular disease incidence in post-thyroidectomy thyroid cancer patients.

\begin{tabular}{|c|c|c|c|c|}
\hline & \multicolumn{2}{|c|}{ Coronary heart disease } & \multicolumn{2}{|c|}{ Ischemic stroke } \\
\hline & $\operatorname{aHR}(95 \% \mathrm{Cl})^{\star}$ & $P$-value & $\operatorname{aHR}(95 \% \mathrm{Cl})^{*}$ & $P$-value \\
\hline Age, 10 years & $1.05(1.05-1.05)$ & $<0.001$ & $1.08(1.07-1.08)$ & $<0.001$ \\
\hline \multicolumn{5}{|l|}{ Sex } \\
\hline Male & 1 & & 1 & \\
\hline Female & $0.75(0.69-0.82)$ & $<0.001$ & $1.06(0.95-1.17)$ & 0.303 \\
\hline \multicolumn{5}{|l|}{ Insurance premium level } \\
\hline Low & 1 & & 1 & \\
\hline Middle & $0.96(0.83-1.11)$ & 0.565 & $0.84(0.74-0.97)$ & 0.014 \\
\hline High & $0.99(0.87-1.13)$ & 0.888 & $0.75(0.66-0.84)$ & $<0.001$ \\
\hline Hypertension & $2.15(1.98-2.33)$ & $<0.001$ & $1.67(1.54-1.81)$ & $<0.001$ \\
\hline Diabetes & $1.23(1.13-1.34)$ & $<0.001$ & $1.22(1.12-1.33)$ & $<0.001$ \\
\hline Dyslipidemia & $1.39(1.28-1.50)$ & $<0.001$ & $1.12(1.03-1.21)$ & 0.006 \\
\hline \multicolumn{5}{|l|}{ Type of surgery } \\
\hline Unilateral lobectomy & 1 & & 1 & \\
\hline Total thyroidectomy & $0.87(0.73-1.03)$ & 0.109 & $1.02(0.84-1.24)$ & 0.874 \\
\hline \multicolumn{5}{|c|}{ Levothyroxine dosage, quartile } \\
\hline$<115 \mu \mathrm{g} /$ day & $1.41(1.26-1.58)$ & $<0.001$ & $1.31(1.16-1.47)$ & $<0.001$ \\
\hline 115-144 $\mu \mathrm{g} /$ day & 1 & & 1 & \\
\hline $145-169 \mu \mathrm{g} /$ day & $1.61(1.45-1.80)$ & $<0.001$ & $1.63(1.46-1.82)$ & $<0.001$ \\
\hline$\geq 170 \mu \mathrm{g} /$ day & 2.15 (1.94-2.39) & $<0.001$ & 2.15 (1.94-2.39) & $<0.001$ \\
\hline
\end{tabular}

However, it appears that ischemic stroke associated with atrial fibrillation accounts for only a small proportion of ischemic stroke incidence $(4.4 \%$, 128/2914) and patients who took a higher levothyroxine dosage but did not develop atrial fibrillation also had a 1.5 times higher risk of developing ischemic stroke, suggesting that other pathophysiologic pathways may be involved independent of cardioembolic stroke. Systolic hypertension, arterial stiffness and hypercoagulability were suggested as potential mechanisms (22) and warrant further investigation. Although atrial fibrillation is often undiagnosed and not claimed for medical treatment, it is routinely checked upon occurrence of ischemic stroke. A low incidence of atrial fibrillation even in patients who developed ischemic stroke, together with our generally younger, predominantly female population, suggest that atrial fibrillation is not a main factor associated with ischemic stroke.

Another notable finding was the J-shaped risk patterns associated with levothyroxine dosage. Subjects in the 3rd and 4th quartiles of mean levothyroxine dosage administered showed a clear dose-response relationship, supporting the mechanisms discussed above. Subjects in the 1st quartile also showed a higher risk than those in the 2nd quartile, suggesting potential risk elevation in patients with overt or subclinical hypothyroidism. This is consistent with findings of a previous study showing that patients with high TSH levels and those with suppressed TSH levels on long-term levothyroxine therapy for non-cancer diseases are both at risk of developing cardiovascular disease or dysrhythmia (27). Patients may be in hypothyroid states when suboptimal dosages of levothyroxine are prescribed or when patients are not compliant with medication. Consistent with a wide array of evidence linking hypothyroidism and cardiovascular disease, such as dyslipidemia and increase in LDL oxidation (21), atherosclerosis (28), diastolic hypertension (29), dysrhythmia and CHD (30), our results suggest it is important to prescribe the optimal dosage of levothyroxine and monitor TSH levels in order to avoid exposure to hypothyroidism and its complications.

Interestingly, patients in the 2nd quartile for mean dosage of levothyroxine administered showed an even lower risk of developing CHD or ischemic stroke than non-cancer controls. It is probable that this group had normal or near normal TSH levels and did not have an increased cardiovascular risk relative to controls. In Korea, thyroid cancer screening by ultrasonography is provided without any referral at the patient's own cost (approximately 40-200 USD), mainly through private health screening programs. This explains why our study subjects were in higher income ranks compared with the general population. Those who elect to receive health screening are more likely to be engaged in healthier behavior (e.g., not smoking) and receive more attentive preventive treatment (e.g., antihypertensive agents, statins and aspirin) (16). When considering this screenee effect, our estimation of increased cardiovascular risk is 
Table 3 Factors associated with cardiovascular disease incidence in post-thyroidectomy thyroid cancer patients: subgroup analysis with smoking and body weight data $(n=112129)$. Body weight and smoking data within 2 years from date of thyroidectomy was retrieved from the National Health Insurance health screening program data, and a total of 112129 subjects $(61.5 \%)$ were included in the subgroup analysis.

\begin{tabular}{|c|c|c|c|c|}
\hline & \multicolumn{2}{|c|}{ Coronary heart disease } & \multicolumn{2}{|c|}{ Ischemic stroke } \\
\hline & $\operatorname{aHR}(95 \% \mathrm{Cl})^{*}$ & $P$-value & aHR $(95 \% \mathrm{Cl})^{*}$ & $P$-value \\
\hline Age, 10 years & $1.05(1.04-1.05)$ & $<0.001$ & $1.08(1.07-1.08)$ & $<0.001$ \\
\hline \multicolumn{5}{|l|}{ Sex } \\
\hline Male & 1 & & 1 & \\
\hline Female & $0.70(0.61-0.81)$ & $<0.001$ & $0.99(0.84-1.17)$ & 0.909 \\
\hline \multicolumn{5}{|l|}{ Insurance premium level } \\
\hline Low & 1 & & 1 & \\
\hline Middle & $0.98(0.81-1.20)$ & 0.880 & $0.94(0.78-1.14)$ & 0.537 \\
\hline High & $1.04(0.87-1.25)$ & 0.674 & $0.84(0.70-0.99)$ & 0.038 \\
\hline Hypertension & $2.06(1.86-2.29)$ & $<0.001$ & $1.74(1.56-1.93)$ & $<0.001$ \\
\hline Diabetes & $1.26(1.13-1.40)$ & $<0.001$ & $1.24(1.11-1.39)$ & $<0.001$ \\
\hline Dyslipidemia & $1.45(1.31-1.60)$ & $<0.001$ & $1.10(0.99-1.22)$ & 0.080 \\
\hline \multicolumn{5}{|l|}{ Smoking } \\
\hline Never smoker & 1 & & 1 & \\
\hline Former smoker & $0.95(0.77-1.18)$ & 0.664 & $1.10(0.87-1.40)$ & 0.438 \\
\hline Current smoker & $1.15(0.95-1.40)$ & 0.143 & $1.28(1.04-1.58)$ & 0.023 \\
\hline \multicolumn{5}{|l|}{ Type of surgery } \\
\hline Unilateral lobectomy & 1 & & 1 & \\
\hline Total thyroidectomy & $0.87(0.69-1.09)$ & 0.232 & $1.17(0.89-1.54)$ & 0.265 \\
\hline \multicolumn{5}{|c|}{ Levothyroxine dose, quartile } \\
\hline$<1.90 \mu \mathrm{g} / \mathrm{day} \cdot \mathrm{kg}$ & $1.17(1.02-1.34)$ & 0.027 & $1.23(1.05-1.43)$ & 0.009 \\
\hline $1.90-2.32 \mu \mathrm{g} /$ day $\cdot \mathrm{kg}$ & 1 & & 1 & \\
\hline $2.32-2.75 \mu \mathrm{g} / \mathrm{day} \cdot \mathrm{kg}$ & $1.21(1.06-1.38)$ & 0.004 & $1.46(1.26-1.68)$ & $<0.001$ \\
\hline$\geq 2.75 \mu \mathrm{g} / \mathrm{day} \cdot \mathrm{kg}$ & $1.32(1.16-1.50)$ & $<0.001$ & $1.84(1.61-2.11)$ & $<0.001$ \\
\hline
\end{tabular}

likely to be conservative. A similar J-shaped risk pattern was also observed for fracture in our previous study (14).

Although the data are inconclusive due to the small number of thyroid cancer patients who received unilateral thyroidectomy, it appears that the risk of developing CHD and ischemic stroke is not evidently increased in this group. Until recently, surgeons tended to favor total thyroidectomy due to the fear of recurrence and for the ease of postsurgical radioactive iodine ablation and follow-up with thyroglobulin (2). Indeed, only $3.6 \%$ of all thyroid cancer patients in our study received unilateral lobectomy, and the situation is not much different in other countries such as in the United States, where 75\% of those with papillary carcinoma smaller than $1 \mathrm{~cm}$ were reported to have received total thyroidectomy (31). As addressed in the recent update of the American Thyroid Association guidelines (19), our study suggests that more caution is needed in choosing the type of thyroidectomy and appropriate levothyroxine prescription.

Our study is also noteworthy in the context of the recent controversy regarding overdiagnosis and overtreatment of thyroid cancer $(32,33)$. Most of the recent surge in thyroid cancer incidence has been attributed to the detection of clinically occult microcarcinoma, and $>90 \%$ of thyroid cancers are differentiated thyroid cancer, the most indolent type $(19,34)$. If the long-term risk of cardiovascular events revealed in our study is additionally taken into consideration, the benefits of screening and aggressive therapy would be mitigated to some degree. The US Preventive Services Task Force (USPSTF) recently recommended against screening for thyroid cancer in asymptomatic adults (20).

Strengths of this study include inclusion of almost the entire population thus maximizing the representativeness, minimal follow-up loss, and proper selection of control subjects extensively matched for various sociodemographic and major cardiovascular risk factors.

However, we acknowledge that there are several limitations and possible biases to our study. First, we used levothyroxine dosage as a proxy marker for the level of TSH suppression, as our claims data do not include results of thyroid function tests such as free T4 and/or TSH. Although those factors are correlated, serum TSH level with the same dosage of levothyroxine may be different by age, sex, body weight and metabolism. 
Also, actual compliance with prescriptions for levothyroxine could not be taken into consideration. Therefore, we could not make specific interpretations about optimal TSH target levels in terms of cardiovascular disease risk. Second, our study is at risk of bias from non-inclusion of clinical data on type of thyroid cancer or stage, and details of treatments (e.g. high radio-iodine dosage, tyrosine kinase inhibitors). However, nearly all thyroid cancer cases in Korea are diagnosed as differentiated thyroid cancer at localized stage $(32,34,35)$, and it is not likely that the thyroid cancer type and/or stage affect cardiovascular risk. Third, as our study is based on claims data, we did not have detailed clinical information on cardiovascular risk factors at baseline. However, there is no reason to believe there is a systematic difference in cardiovascular risk factors between thyroid cancer patients and controls, and we have controlled for past diagnosis of hypertension, diabetes mellitus, and dyslipidemia, as well as other baseline demographics. Finally, the follow-up period was relatively short and the cumulative effects of longterm TSH suppression need to be established in longer prospective studies.

\section{Conclusions}

In conclusion, the risk of $\mathrm{CHD}$ and ischemic stroke was higher in thyroid cancer patients who received thyroidectomy, and levothyroxine dosage appears to play a major role in this association. As addressed by recently revised guidelines, the results of our study call for more caution in the screening and treatment of thyroid cancer and subsequent TSH suppression therapy. As this particular population represents subjects with heightened risk for cardiovascular disease independent of major cardiovascular risk factors, particularly in those administered with high dosage of levothyroxine, more meticulous management strategies for cardiovascular disease prevention appear to be warranted.

\section{Declaration of interest}

The authors declare that there is no conflict of interest that could be perceived as prejudicing the impartiality of this study.

\section{Funding}

This study was supported by a NHIS Ilsan Hospital Grant (NHIMC 2015-20-006).

\section{Author contribution statement}

Beomseok Suh: conceptualization, data curation, formal analysis, writing - original draft; Dong Wook Shin: conceptualization, data curation, formal analysis, writing - review and editing; Youngmin Park: conceptualization, funding acquisition, project administration, supervision, resources; Hyunsun Lim: formal analysis, methodology, project administration; Jae Moon Yun; formal analysis, methodology; Sun Ok Song: writing review and editing; Jin Ho Park: writing - review and editing; BeLong Cho: conceptualization, writing - review and editing; Eliseo Guallar: methodology, writing - review and editing.

\section{Acknowledgement}

The authors alone are responsible for the content and writing of the paper. This work was presented at the American Society of Clinical Oncology (ASCO) survivorship symposium on January 28, 2017 in San Diego, CA.

\section{References}

1 American Thyroid Association Guidelines Taskforce on Thyroid N, Differentiated Thyroid C, Cooper DS, Doherty GM, Haugen BR, Kloos RT, Lee SL, Mandel SJ, Mazzaferri EL, McIver B, Pacini F, Schlumberger $\mathrm{M}$ et al. Revised American Thyroid Association management guidelines for patients with thyroid nodules and differentiated thyroid cancer. Thyroid 200919 1167-1214. (https:// doi.org/10.1089/thy.2009.0110)

2 Pacini F, Schlumberger M, Dralle H, Elisei R, Smit JW \& Wiersinga W. European consensus for the management of patients with differentiated thyroid carcinoma of the follicular epithelium. European Journal of Endocrinology 2006154 787-803. (https://doi. org/10.1530/eje.1.02158)

3 Sawin CT, Geller A, Wolf PA, Belanger AJ, Baker E, Bacharach P, Wilson P, Benjamin EJ \& D'Agostino RB. Low serum thyrotropin concentrations as a risk factor for atrial fibrillation in older persons. New England Journal of Medicine 1994331 1249-1252. (https://doi. org/10.1056/NEJM199411103311901)

4 Dörr M, Empen K, Robinson DM, Wallaschofski H, Felix SB \& Völzke H. The association of thyroid function with carotid artery plaque burden and strokes in a population-based sample from a previously iodine-deficient area. European Journal of Endocrinology 2008159 145-152. (https://doi.org/10.1530/EJE-08-0140)

5 Peters A, Ehlers M, Blank B, Exler D, Falk C, Kohlmann T, Fruehwald-Schultes B, Wellhoener P, Kerner W \& Fehm HL. Excess triiodothyronine as a risk factor of coronary events. Archives of Internal Medicine $20001601993-1999$.

6 Biondi B \& Cooper DS. Benefits of thyrotropin suppression versus the risks of adverse effects in differentiated thyroid cancer. Thyroid 2010 20 135-146. (https://doi.org/10.1089/thy.2009.0311)

7 Abonowara A, Quraishi A, Sapp JL, Alqambar MH, Saric A, O'Connell CM, Rajaraman MM, Hart RD \& Imran SA. Prevalence of atrial fibrillation in patients taking TSH suppression therapy for management of thyroid cancer. Clinical and Investigative Medicine 201235 E152-E156. (https://doi.org/10.25011/cim.v35i3.16591)

8 Smit J, Eustatia-Rutten C, Corssmit E, Pereira A, Frolich M, Bleeker G, Holman E, Van Der Wall E, Romijn J \& Bax J. Reversible diastolic dysfunction after long-term exogenous subclinical hyperthyroidism: a randomized, placebo-controlled study. Journal of Clinical Endocrinology and Metabolism 200590 6041-6047. (https://doi. org/10.1210/jc.2005-0620)

9 Shargorodsky M, Serov S, Gavish D, Leibovitz E, Harpaz D \& Zimlichman R. Long-term thyrotropin-suppressive therapy with levothyroxine impairs small and large artery elasticity and increases 
left ventricular mass in patients with thyroid carcinoma. Thyroid 200616 381-386. (https://doi.org/10.1089/thy.2006.16.381)

10 Hesselink ENK, Hesselink MSK, de Bock GH, Gansevoort RT, Bakker SJ, Vredeveld EJ, van der Horst-Schrivers AN, van der Horst IC, Kamphuisen PW \& Plukker JT. Long-term cardiovascular mortality in patients with differentiated thyroid carcinoma: an observational study. Journal of Clinical Oncology 201331 4046-4053. (https://doi.org/10.1200/JCO.2013.49.1043)

11 Pajamaki N, Metso S, Hakala T, Ebeling T, Huhtala H, Ryodi E, Sand J, Jukkola-Vuorinen A, Kellokumpu-Lehtinen PL \& Jaatinen P. Longterm cardiovascular morbidity and mortality in patients treated for differentiated thyroid cancer. Clinical Endocrinology 201888 303-310. (https://doi.org/10.1111/cen.13519)

12 Seong SC, Kim YY, Khang YH, Heon Park J, Kang HJ, Lee H, Do CH, Song JS, Hyon Bang J, Ha S et al. Data Resource Profile: The National Health Information Database of the National Health Insurance Service in South Korea. International Journal of Epidemiology 201646 799-800. (https://doi.org/10.1093/ije/dyw253)

13 Shin DW, Cho B \& Guallar E. Korean National Health Insurance database. JAMA Internal Medicine 2016176 138-138. (https://doi. org/10.1001/jamainternmed.2015.7110)

14 Shin DW, Suh B, Lim H, Yun JM, Song SO \& Park Y. J-shaped association between postoperative levothyroxine dosage and fracture risk in thyroid cancer patients: a retrospective cohort study. Journal of Bone and Mineral Research 201833 1037-1043. (https://doi.org/10.1002/jbmr.3407)

15 Rubin DB. On principles for modeling propensity scores in medical research. Pharmacoepidemiology and Drug Safety 200413 855-857. (https://doi.org/10.1002/pds.968)

16 Lee H, Cho J, Shin DW, Lee SP, Hwang SS, Oh J, Yang HK, Hwang SH, Son KY, Chun SH et al. Association of cardiovascular health screening with mortality, clinical outcomes, and health care cost: a nationwide cohort study. Preventive Medicine 201570 19-25. (https://doi. org/10.1016/j.ypmed.2014.11.007)

17 Biondi B \& Cooper DS. The clinical significance of subclinical thyroid dysfunction. Endocrine Reviews 200829 76-131. (https://doi. org/10.1210/er.2006-0043)

18 Devdhar M, Drooger R, Pehlivanova M, Singh G \& Jonklaas J. Levothyroxine replacement doses are affected by gender and weight, but not age. Thyroid 201121 821-827. (https://doi.org/10.1089/ thy.2011.0029)

19 Haugen BR, Alexander EK, Bible KC, Doherty GM, Mandel SJ, Nikiforov YE, Pacini F, Randolph GW, Sawka AM \& Schlumberger M. 2015 American Thyroid Association management guidelines for adult patients with thyroid nodules and differentiated thyroid cancer: the American Thyroid Association Guidelines Task Force on Thyroid Nodules and Differentiated Thyroid Cancer. Thyroid 201626 1-133. (https://doi.org/10.1089/thy.2015.0020)

20 U. S. Preventive Services Task Force, Bibbins-Domingo K, Grossman DC, Curry SJ, Barry MJ, Davidson KW, Doubeni CA, Epling JW Jr, Kemper AR, Krist AH, Kurth AE et al. Screening for thyroid cancer: US Preventive Services Task Force Recommendation Statement. JAMA 2017317 1882-1887. (https://doi.org/10.1001/ jama.2017.4011)

21 Sundaram V, Hanna AN, Koneru L, Newman HA \& Falko JM. Both hypothyroidism and hyperthyroidism enhance low density lipoprotein oxidation. Journal of Clinical Endocrinology and Metabolism 199782 3421-3424.
22 Sheu JJ, Kang JH, Lin HC \& Lin HC. Hyperthyroidism and risk of ischemic stroke in young adults: a 5-year follow-up study. Stroke 201041 961-966. (https://doi.org/10.1161/ STROKEAHA.109.577742)

23 Collet TH, Gussekloo J, Bauer DC, den Elzen WP, Cappola AR, Balmer P, Iervasi G, Asvold BO, Sgarbi JA, Volzke H et al. Subclinical hyperthyroidism and the risk of coronary heart disease and mortality. Archives of Internal Medicine 2012172 799-809.

24 Squizzato A, Gerdes VE, Brandjes DP, Buller HR \& Stam J. Thyroid diseases and cerebrovascular disease. Stroke 200536 2302-2310. (https://doi.org/10.1161/01.STR.0000181772.78492.07)

25 January CT, Calkins H, Murray KT, Cigarroa JE \& Stevenson WG. 2014 AHA/ACC/HRS Guideline for the management of patients with atrial fibrillation. Circulation 2014129 2071-2104. (https://doi. org/10.1161/CIR.0000000000000040)

26 Camm AJ, Lip GY, De Caterina R, Savelieva I, Atar D, Hohnloser SH, Hindricks G, Kirchhof P, Bax JJ \& Baumgartner H. 2012 focused update of the ESC Guidelines for the management of atrial fibrillation: an update of the 2010 ESC Guidelines for the management of atrial fibrillation. European Heart Journal 201233 2719-2747. (https://doi.org/10.1093/eurheartj/ehs253)

27 Flynn RW, Bonellie SR, Jung RT, MacDonald TM, Morris AD \& Leese GP. Serum thyroid-stimulating hormone concentration and morbidity from cardiovascular disease and fractures in patients on long-term thyroxine therapy. Journal of Clinical Endocrinology and Metabolism 201095 186-193. (https://doi.org/10.1210/ jc.2009-1625)

28 O'Brien T, Dinneen SF, O'Brien PC \& Palumbo PJ. Hyperlipidemia in patients with primary and secondary hypothyroidism. Mayo Clinic Proceedings 199368 860-866.

29 Fommei E \& Iervasi G. The role of thyroid hormone in blood pressure homeostasis: evidence from short-term hypothyroidism in humans. Journal of Clinical Endocrinology and Metabolism 200287 1996-2000. (https://doi.org/10.1210/jcem.87.5.8464)

30 Kandan SR \& Saha M. Severe primary hypothyroidism presenting with torsades de pointes. BMJ Case Reports 20122012.

31 Davies L \& Welch HG. Increasing incidence of thyroid cancer in the United States, 1973-2002. JAMA 2006295 2164-2167. (https://doi. org/10.1001/jama.295.18.2164)

32 Ahn HS, Kim HJ \& Welch HG. Korea's thyroid-cancer "epidemic" screening and overdiagnosis. New England Journal of Medicine 2014 371 1765-1767. (https://doi.org/10.1056/NEJMp1409841)

33 Esserman LJ, Thompson IM, Reid B, Nelson P, Ransohoff DF, Welch HG, Hwang S, Berry DA, Kinzler KW \& Black WC. Addressing overdiagnosis and overtreatment in cancer: a prescription for change. Lancet Oncology 201415 e234-e242. (https://doi.org/10.1016/S14702045(13)70598-9)

34 Park S, Oh CM, Cho H, Lee JY, Jung KW, Jun JK, Won YJ, Kong HJ, Choi KS, Lee YJ et al. Association between screening and the thyroid cancer "epidemic" in South Korea: evidence from a nationwide study. BMJ 2016355 i5745. (https://doi.org/10.1136/ bmj.i5745)

35 Cho BY, Choi HS, Park YJ, Lim JA, Ahn HY, Lee EK, Kim KW, Yi KH, Chung JK, Youn YK et al. Changes in the clinicopathological characteristics and outcomes of thyroid cancer in Korea over the past four decades. Thyroid 201323 797-804. (https://doi.org/10.1089/ thy.2012.0329)

Received 2 July 2018

Revised version received 13 September 2018

Accepted 9 October 2018 